\title{
Sueño, poesía y realidad latinoamericana en Me alquilo para soñar, de Gabriel García Márquez.
}

\author{
Dream, Poetry and Latin American Reality in Gabriel García Márquez's Me alquilo \\ para soñar.
}

DOI: $10.32870 /$ sincronia.axxv.n79.17a21

\author{
Seohyeok Park \\ Universidad Nacional de Seúl (COREA DEL SUR)
}

CE: pshyeok@snu.ac.kr

Esta obra está bajo una Licencia Creative Commons Atribución-NoComercial 4.0 Internacional

Recibido: $20 / 09 / 2020$

Revisado: 03/10/2020

Aprobado: $12 / 11 / 2020$

\section{RESUMEN}

Este artículo revisa la configuración del sueño como lo fantástico y la poesía como una más de las dimensiones de la realidad, en el cuento "Me alquilo para soñar" de García Márquez. Se destacan las dimensiones en que se mueven los tres personajes principales: la vida-sueño, la vida-poesía y la vida-narración, que comparten como base común la creación. El objetivo central es mostrar que el mecanismo de creación es el mismo, la recreación imaginativa, y analizar la estrategia de verosimilitud en donde se añade el punto de vista de la experiencia por parte del lector, a fin de revisar la realidad de los latinoamericanos que se presenta al lector en este cuento.

Palabras Clave: Recreación. Verosimilitud. Lector. Soledad. Europa.

\section{ABSTRACT}

The present article reviews the configuration of dream as the fantastic and poetry as another dimension of reality, in the short story "Me alquilo para soñar" by García Márquez. Three dimensions are highlighted in which three main characters are embodied: the life-dream, the life-poetry and the life-narrative, which share creation as a common foundation. The main objective is to demonstrate that the mechanism of creation is the same, the imaginative recreation, and to analyze the strategy 
of verisimilitude conjoining the perspective of the experience of the reader, in order to scrutinize the reality of Latin Americans who are presented to the reader in this short story.

Keywords: Recreation. Verisimilitude. Reader. Solitude. Europe.

\section{Introducción}

Gabriel García Márquez es uno de los escritores más leídos en Corea. En los años 80, “la narrativa de García Márquez que universalizó el concepto de realismo mágico influyó significativamente en la literatura coreana" (Lee, 2019, p. 180). Lee cita obras de autores como Seong-Dong Kim, Sok-Yong Hwang y Chul-Woo Im para afirmar que "el Premio Nobel sacudió la sensibilidad de los escritores obligados a guardar silencio bajo el autoritarismo militar de Doo-Hwan Chun" (Lee, 2019, p. 180). Sin embargo, no solo el realismo mágico influyó sino la manera en que García Márquez combinaba la realidad con la ficción.

En su discurso de aceptación del Premio Nobel, "La soledad de América Latina" (2014), García Márquez expresó que la realidad increíble formulada en la literatura latinoamericana era la representación fiel de la realidad objetiva de la región (pp. 167-170). Brushwood (1985, pp. 9-14) afirma que la escritura de García Márquez incorpora la vida real experimentada por el autor, las historias que se le contaron y la imaginación, creando el efecto de que el lector se sumerja en el texto y al mismo tiempo contemple la realidad. González Echevarría (1984, pp. 358-380), desde otra perspectiva, sugiere que su literatura tiene la capacidad de capturar la historia de América Latina a través de la combinación de los componentes míticos y la historia archivada. La crítica coincide en que, a pesar de la riqueza de imaginación y la apariencia de lo fantástico, la realidad de América Latina está en el epicentro de las obras de García Márquez. La narración de los textos pretende crear un efecto por el cual los lectores se enfoquen en la verdad en vez de simplemente disfrutar la lectura de maravillas.

En el prólogo de Doce cuentos peregrinos (2002), el escritor plantea la cuestión de la realidad de los latinoamericanos. Confiesa que tuvo un sueño en el que asistió a su propio funeral y que este 
sueño le pareció como "un punto de partida para escribir sobre las cosas extrañas que les suceden a los latinoamericanos en Europa" (García, 1992, p. 14). Añade que el sueño (lo fantástico) es la reflexión más fiel de la realidad objetiva (lo real). Desde el prólogo, se observa el mismo propósito del escritor de capturar y representar la realidad latinoamericana que se expresa mejor con los componentes fantásticos.

A la fecha, no se observan suficientes estudios ni análisis de Doce cuentos peregrinos desde ese punto de vista. Houvenaghel (1999, pp. 59-71) analiza la estrategia de verosimilitud presente en los cuentos que hace creíbles las historias inimaginables que se relatan, sintetizando técnicas retóricas de la novela, como el distanciamiento y la cotidianidad. Sin embargo, no destaca el mecanismo por el cual el lector se comunica con ambos, el texto y la temática, para interpretar el sentido del cuento. Por otra parte, los estudios que analizan el significado de la realidad en los cuentos no consideran los componentes estilísticos. Nuestro objetivo, por consiguiente, es analizar la estrategia de verosimilitud, añadiendo el punto de vista de la experiencia por parte del lector, a fin de revisar la realidad de los latinoamericanos que el autor ofrece al lector en dichos cuentos. Nos centraremos en "Me alquilo para soñar", el cuarto cuento de la colección, que incorpora el sueño como lo fantástico y la poesía como una más de las dimensiones de la realidad. En dicho cuento, Neruda representa a la poesía: “El escritor latinoamericano más querido y reconocido en los 70 en Corea [...], no solo por su mundo poético, sino también por su pensamiento revolucionario" (Lee, 2019, p. 180).

\section{El texto verosímil y la participación del lector}

García Márquez escribe en el prólogo de la colección que después de revisitar algunas ciudades europeas que conforman los espacios de los doce relatos, se dio cuenta de que su memoria de las ciudades no tenía ninguna semejanza con la actualidad. Esta experiencia le hizo pensar que la vida y la imaginación no se distinguen en la escritura. Por ello, se podría decir que la realidad que materializa García Márquez en Doce cuentos peregrinos mezcla lo real y lo imaginado representado 
por el sueño, con el fin de capturar la vida real que se expresa irónicamente mejor con la imaginación.

La relación entre la realidad objetiva y la imaginación está en el epicentro tanto del estilo como del tema de los doce relatos que se basan en hechos probables desde el punto de vista de lo real y que, al mismo tiempo, relatan lo extraño que objetivamente no podría suceder en el mundo real. Especialmente, en "Me alquilo para soñar" se oscurece la distinción entre lo real y lo fantástico, y el foco se traslada al tema central: el verdadero significado de la vida de Frau Frida, la protagonista que soñaba e interpretaba los sueños para sobrevivir en la ciudad austriaca donde Freud escribió La interpretación de los sueños. Aunque la profeta-soñadora representa lo fantástico, el lector para de preguntarse acerca de la credibilidad de la fantasía que se presenta dentro del texto y pasa a contemplar cómo vivió la protagonista y cuál sería el significado verdadero de vivir.

Además de la vida real y la imaginación, se agrega la dimensión de la poesía. Con la aparición de Pablo Neruda en la narración, se compara el sueño y la poesía. Es este punto donde el texto ofrece al lector un espacio más para reflexionar sobre la naturaleza onírica y creativa de la vida, cuando yuxtapone la vida, el sueño y la poesía, invitando al lector a contemplar esa relación. En consecuencia, los lectores experimentan que estas tres dimensiones se entretejen y que los límites entre ellas empiezan a diluirse. Esas tres dimensiones acaban por disolverse formando un mundo autónomo dentro del texto. Así, no se causa una sensación de rareza a pesar de la mezcla de la realidad objetiva con los componentes supuestamente increíbles. La narración alcanza la verosimilitud y establece un mundo dentro del texto que no se ve interferido por las leyes del mundo real y que queda a la interpretación y contemplación del lector.

\section{Las estrategias de la verosimilitud}

A la luz de las teorías de Aristóteles, Genette y Matamoro, Houvenaghel define la verosimilitud literaria como "una variable histórica determinada por la imagen ideal que el lector se ha forjado de la realidad" (p. 60), sobre la cual determina las estrategias que contribuyen a la verosimilitud en 
Doce cuentos peregrinos. Entre otras, estas dos que tomaremos para nuestro cuento: la toma de distancia y el uso de la historia como documento.

La toma de distancia se realiza de dos maneras. Primera, la distancia entre el narrador y la protagonista. El narrador de "Me alquilo para soñar" es narrador-personaje y cuenta la historia de la vida de Frau Frida en primera persona. Como un personaje más, el narrador es un testigo. También es el único focalizador del cuento, siguiendo el término de Mieke Bal. ${ }^{1}$ Este tipo de narrador tiene un grado de conocimiento limitado. Cuenta desde su experiencia y sus propios conocimientos sobre la mujer, lo cual deja al lector sin entender enteramente qué tipo de persona era Frau Frida ni qué pasó exactamente durante el tiempo en que los dos no tuvieron contacto, porque el narradorpersonaje no puede contar sino lo que vio o escuchó. Otra característica particular del narrador es que en uno de los saltos al pasado casi se convierte en narrador externo, contando desde la tercera persona el pasado de la protagonista. Durante la segunda vuelta al pasado, la primera persona no se usa, sino que todas las oraciones están en tercera persona:

A los siete años soñó [Frau Frida] que uno de sus hermanos era arrastrado por un torrente. La madre, por pura superstición religiosa, le prohibió al niño lo que más le gustaba, que era bañarse en la quebrada. Pero Frau Frida tenía ya un sistema propio de vaticinos.

-Lo que ese sueño significa - dijo- no es que se vaya a ahogar, sino que no debe comer dulces. (García, 1992, pp. 95-96).

En esa parte del cuento, la única protagonista es Frida y otros personajes son su familia y las familias austriacas. El narrador-personaje desaparece y queda fuera de la narración, comportándose o transformándose en un narrador omnisciente, aunque solo está contando lo que habría escuchado de la mujer. Esto tiene que ver con la noción de la realidad como una recreación. El narrador-personaje está recordando lo que escuchó, pero si tenemos en cuenta la poética de García Márquez explicitada en el prólogo sobre cómo el tiempo oscurece los límites entre los recuerdos

1 “La focalización es la relación entre la 'visión', el agente que ve y lo que se ve. [...] El sujeto de la focalización, el focalizador, constituye el punto desde el que se contemplan los elementos". (Bal, 1990, p. 110). Las cursivas son del texto. 
reales y la imaginación, se podría decir que la realidad que se narra en esta parte es una recreación de la vida real. La estructura de la narración convierte de esta manera la realidad objetiva en una realidad compuesta de objetividad y subjetividad.

La segunda forma de distanciamiento es la estructura de los tiempos. El narrador-personaje está en Cuba y el tiempo cronológico del texto son los años 70. Empieza en el presente donde el personaje que narra presencia la muerte de Frau Frida a la que había conocido 34 atrás, y empieza a recordar el pasado compartido con la misteriosa mujer. Después de la retrospección, al final del cuento, la narración vuelve al presente. Esta estructura temporal que empieza y termina en presente con la mayor parte del contenido central en el pasado sirve para enfatizar la distancia temporal que existe entre el tiempo de los recuerdos del narrador-personaje y el presente. Como los acontecimientos del pasado están contados por un personaje dentro del texto, la narración gana un tipo de indulgencia para justificar fallos o absurdidad como resultado de la transmisión infiel de la memoria. La distancia temporal profundiza así la probabilidad de la distorsión de los hechos. Como dice García Márquez en el prólogo:

[...] quise comprobar la fidelidad de mis recuerdos casi veinte años después, y emprendí un rápido viaje de reconocimiento a Barcelona, Ginebra, Roma y París. [...] Todas, como toda la Europa actual, estaban enrarecidas por una inversión asombrosa: los recuerdos reales me parecían fantasmas de la memoria, mientras los recuerdos falsos eran tan convincentes que habían suplantado a la realidad. (1992, p. 18).

El lector, que bien comprende la posibilidad de la ilusión temporal, no duda de la verosimilitud del texto. Lo que cuenta el narrador podría ser falso, pero en el mundo del texto no se ve como tal para el lector. Sin embargo, lo fantástico y lo no explicado sobre la protagonista y su vida sigue existiendo. En esta estructura no se sabe nada de Frau Frida sino a través de lo que cuenta el narrador-personaje. Esto hace que la interpretación de los sueños, la vida y la muerte de la protagonista queden como una verdad parcial y misteriosa. Si el narrador-personaje contara solo sus recuerdos de manera objetiva, perdería verosimilitud. Este problema lo soluciona la segunda 
estrategia: la historia como un documento. La distancia ganada otorga al narrador-personaje un espacio libre para ejecutar sus propios comentarios y su examinación sobre la vida de Frau Frida, como afirma Houvenaghel:

En efecto, se amplifica la historia con procedimientos lógicos y críticos. Se rompe la evidencia de una línea narrativa única mediante la inserción de comentarios y dudas acerca de la verosimilitud de los hechos, clarificaciones sobre el proceso de escritura y otras precisiones. Gracias a estos comentarios, el lector llega a considerar la historia como un documento que fue estudiado y criticado y cuya autenticidad ya se puso en tela de juicio. (1999, p. 69).

El narrador-personaje no solo cuenta la historia, sino que también añade sus pensamientos y juicios sobre lo que habrían pensado y hecho Frida y Neruda. Por ejemplo, el narrador-personaje expresa sus dudas sobre el poder de la protagonista: "siempre había pensado que sus sueños no eran más que una artimaña para vivir" (p. 99). Este acto del narrador convierte lo que narra en un documento y el lector puede confiar en que la historia que se cuenta fue contemplada y verificada.

La distancia temporal permite que la narración obtenga verosimilitud a pesar de su falta de fidelidad, dicha verosimilitud en este cuento, por lo tanto, difiere de la realidad objetiva 'verdadera'. Es más bien un efecto o una condición que el autor logra como muestra de que lo subjetivo o lo no fidedigno también puede ser verosímil gracias a la estructura del tiempo distante y a la historia como un documento.

\section{La experiencia del lector}

Los contextos permiten que el lector del cuento, en vez de solamente sumergirse en el texto, conciba la sensación de tener una comunicación más directa con lo escrito. Así, el lector pasa por la experiencia de interpretar e imaginar lo que quiere decir el texto. Como propone García Márquez, la lectura profunda del cuento lleva al lector a un viaje a través de sus pensamientos sobre el significado de vivir, mediante la relación entre el sueño, la poesía y la realidad de los 
latinoamericanos en Europa representada por la colombiana soñadora. Esta experiencia activa y autónoma del lector supone un espacio extratextual.

El componente que permite la interacción entre el mundo cerrado del texto y el mundo real del lector requiere considerar las relaciones entre sujetos dentro y fuera del texto. Según Seymour Chatman, la estructura narrativa y de comunicación está compuesta como el siguiente esquema:

Mundo real

Autor $\rightarrow$
Texto Narrativo

[ Autor implícito - Narrador - Narratario² - Lector implícito] $\rightarrow$
Mundo real

Lector

Las entidades entre corchetes componen el texto narrativo y un mundo cerrado e independiente dentro del texto el cual, en su autodeterminación, alude el hecho de que el autor ni el lector pueden intervenir en la existencia del mundo textual, como afirma Chatman (1978, pp. 146-151). Esto no significa que la comunicación entre el texto y el mundo real sea imposible. Kim, SeungHwan (2017, p. 36) subraya la existencia de una línea invisible que divide ambos mundos. Irónicamente, según el crítico, la misma línea es la que permite la comunicación entre ambos. Cuanto más verosímil y realista sea la realidad del mundo del texto, más profundamente entra el lector a dicho texto.

En "Me alquilo para soñar", el texto verosímil atrae al lector para salir del mundo real virtualmente durante la lectura y sentirse como si estuviera en el mundo del texto. El efecto de este proceso de cruzar la línea invisible por parte del lector es la participación más bien pasiva de la lectura en la interpretación del texto, de manera que el lector acompaña al lector implícito y al narrador-personaje (el supuesto interlocutor del diálogo del narrador) e interpreta las historias y los comentarios que cuenta sobre Frau Frida.

No obstante, este viaje al mundo del texto no alcanza a crear un tipo de experiencia activa y autónoma para el lector ni tampoco puede explicar cómo la realidad latinoamericana forma el

\footnotetext{
2 La traducción del tecnicismo narratee, usado por Seymour Chatman, es "narratario": "narratario. Del francés narrataire, construido a partir de narrateur. (fr. narrataire, ing. narratee, it. narratario". (Garrido, 2015).
} 
núcleo temático del cuento. El lector necesita un espacio distante del texto donde pueda ejercer sus propias facultades de juicio e imaginación. Bertolt Brecht utiliza la técnica de distanciación "para desmitificar lo que tiene enfrente, cuestionando el modo de ser y estar de las cosas en un momento dado [con el fin de] proveer al espectador la cercanía suficiente, en materia de razonamiento y de placer" (Rodríguez, 2018, p. 75). Por esta razón, el lector necesita mantener distancia para darse cuenta de que la historia está en otro mundo. Esta amplificación de la experiencia del lector está condicionada al espacio fuera del texto. La sensación de distancia, o la alienación, permite "el libre juego de facultades", ${ }^{3}$ siguiendo el término kantiano que Kim, Seung-Hwan (2017, pp. 42-49) utiliza para explicar tal experiencia de la lectura y, desde ahí, la interpretación estética y significativa.

Ahora bien, si alguien que lee "Me alquilo para soñar" alcanza el estado de 'contemplación' desde su propio espacio, ¿a qué se deberá esa ampliación? ¿Qué componente del discurso hace que el lector se dé cuenta de la distancia y contemple de manera crítica? El narrador-personaje, otra vez, contribuye a este proceso. La misma estrategia que condiciona la verosimilitud abre un espacio fuera del texto para que el lector intervenga en su interpretación. Los comentarios que hace el narrador sobre los acontecimientos en la historia aumentan la confiabilidad del texto, porque el lector siente que la historia fue criticada y considerada cuidadosamente por el narrador-personaje.

Por otra parte, que el lector esté de acuerdo con los comentarios del narrador o se oponga a ellos es una cuestión distinta. Aunque el texto mismo sea verosímil, el testimonio queda como una opinión no verificada a la que el lector tiene la opción de juzgar. El narrador-personaje que crea la distancia entre la vida de Frau Frida y el lector no puede ser completamente fidedigno y, como resultado, el lector evalúa la subjetividad del relato para confirmar u oponerse. En este caso, los comentarios del narrador causan la alienación del lector.

El hecho de que el texto sea verosímil no significa que el poder de Frau Frida sea imposible y falso en la historia. Al contrario, el poder fantástico de la protagonista gana la oportunidad de

\footnotetext{
${ }^{3}$ Sobre el "Libre juego de facultades" de Kant, se afirma: "En la Crítica del juicio no encontramos una definición explícita de juego, pero el término, utilizado en muchísimas ocasiones, indica mayormente una libre concordancia de lo diferente, la cual, en cuanto libre, no obedece a ninguna necesidad, sino que es producida originariamente por las facultades subjetivas". (Gabás,1990, p. 43).
} 
someterse al juicio del lector sin verse considerado como imposible. No hay una respuesta única a este juicio, lo importante es que todo es probable en el texto verosímil y que lo fantástico no pertenece al ámbito de lo imposible. Los comentarios del narrador, pues, también están pendientes de verificación. Cuando el narrador comenta que no creía en el poder de Frau Frida, un lector que duda del argumento puede creer que las predicciones sobrenaturales fueron verdad. Este es un punto de partida para la interpretación más allá del mundo del texto. De allí, el lector puede empezar a mirar la vida de la protagonista desde una perspectiva nueva.

Pablo Neruda es otro personaje dentro del texto que advierte al lector sobre el mundo fuera del texto. Es un personaje que simboliza al poeta en el mundo real y su poesía está expresada en sus opiniones y diálogos en el cuento:

La invitamos [a Frau Frida] a tomar el café en nuestra mesa, y la induje a hablar de sus sueños para sorprender al poeta. Él no le hizo caso, pues planteó desde el principio que no creía en adivinaciones de sueños.

-Sólo la poesía es clarividente - dijo. (García, 1992, p. 99)

Como el narrador-personaje, Neruda rechaza el poder de Frida de predecir el futuro mediante la interpretación de sus sueños. El argumento del personaje es coherente con el del poeta en la realidad. Esto fortalece el poder y la autoridad del comentario. Sin embargo, su afirmación de que "solo la poesía" es capaz de producir predicciones de vida es desafiado por su propio sueño que tiene durante la siesta, en donde aparece con Frau Frida: "soñé que ella estaba soñando conmigo dijo él [Neruda]" (p. 100). El lector toma distancia del comentario de Neruda y se pregunta si el poeta tiene razón, y si no, cuál sería el significado que aporta esta unión inesperada. Como resultado, el lector vuelve a mantener la distancia respecto del texto y pasa por un proceso reflexivo e interpretativo, movilizando su razón y el entendimiento del mundo. 


\section{El carácter pluridimensional de la realidad}

Aunque el lector es responsable de su lectura y tiene libertad de interpretar el texto literario, no se puede negar que el autor encamina a la comprensión de ciertas ideas en el texto. El autor implícito crea un equilibrio entre la intención del autor y la libertad del lector, como señala Booth:

As he [author] writes, he creates not simply an ideal, impersonal "man in general" but an implied version of "himself" [...], it is clear that the picture the reader gets of this presence is one of the author's most important effects. However impersonal he may try to be, his reader will inevitably construct a picture of the official scribe who writes in this manner.

[Como escribe [el autor], no crea simplemente un "hombre en general" ideal e impersonal, sino una versión implícita de "sí mismo" [...], está claro que la imagen que el lector obtiene de esta presencia, es una de los efectos más importantes. Por impersonal que intente ser, su lector inevitablemente construirá una imagen del escriba oficial que escribe de esta manera]. (1983, pp. 70-71).

La intención de García Márquez que se encontraría en el cuento "Me alquilo para soñar" estaría explícita en el prólogo de la colección. El tema central de los doce textos del volumen, según afirma, está vinculado con "las cosas extrañas que les suceden a los latinoamericanos en Europa" (García, 1992, p. 14), y la clave de esa extrañeza sería la realidad que se parece al sueño y a la poesía.

\section{La vida como creación onírica y poética}

Cada uno de los tres personajes del cuento simboliza una distinta visión del mundo. Pablo Neruda representa la poesía, como en el mundo real. Frida es el personaje que encarna el sueño. Hábil en la interpretación de sueños, es su único interés y propósito de vida. Su carácter está vinculado al sueño. El narrador-personaje aporta una visión enclavada en la vida real. No cree en el poder premonitorio del sueño ni en la interpretación de sueños de Frida; para este personaje priman las reglas racionales. Así, las relaciones y las dinámicas entre los tres personajes no solo forman el eje central del discurso, sino que tienden un triángulo entre los significados en torno a la vida. 
Las dimensiones del sueño y la poesía están dispuestas en un cierto tipo de enfrentamiento. La afirmación de Neruda de que la poesía es lo único clarividente es un acto que deprecia la actividad de Frida. Neruda cree en la fuerte distinción entre poesía y sueño y la enuncia de forma autoritaria. Según el poeta, la esencia de la poesía es la clarividencia, mientras que el sueño no posee esa virtud. Sin embargo, el rechazo por parte de Neruda, pronto se ve negado cuando el poeta y Frida sueñan entre sí:

-Soñé con esa mujer que sueña - dijo [Neruda].

Matilde quiso que le contara el sueño.

—Soñé que ella estaba soñando conmigo —-dijo él.

$[\ldots]$

-Soñé con el poeta — nos dijo [Frau Frida].

Asombrado, le pedí que me contara el sueño.

Soñé que él estaba soñando conmigo -dijo [...]. (García, 1992, pp. 100-101)

La poesía interacciona con el sueño, finalmente. En el clímax del cuento, se sugiere que la poesía y el sueño podrían estar estrechamente relacionados. El encuentro onírico de Frida y Neruda simbolizaría la conciliación entre estos elementos originalmente enfrentados en el cuento, al tiempo que destaca la ironía de la semejanza entre la poesía y el sueño.

¿Qué es lo común compartido por el sueño y la poesía? La poesía crea un significado nuevo en las cosas ordinarias. La poesía libera la realidad y le concede la arbitrariedad que crea algo nuevo. La clarividencia poética no se limita a un papel pasivo y diagnóstico, sino que avanza hasta cumplir actos transformativos: dar una nueva vida a sus materiales. Shelley (1998, pp. 944-956), poeta inglés del siglo XVIII, afirmó que la poesía controla la facultad creativa del humano gracias al poder del lenguaje, y que revela la belleza escondida del mundo al reproducir todo lo que representa. Esto es justo lo que hace Frida con sus sueños. Interpreta el sueño y le asigna una interpretación, creando un significado acerca de la vida a partir del sueño. Las predicciones de la protagonista configuran un conjunto que suma la objetividad y la arbitrariedad, la verdad y la 
imaginación. En este sentido, el acto de soñar sería la poesía por excelencia. ${ }^{4}$ La conciliación entre el sueño y la poesía sería una metáfora del poder de creación que sustentan los dos personajes, el poeta y la soñadora. Frida crea realidades con sus sueños y Neruda con su poesía. Los dos soñando juntos es una declaración de que, en el fondo, el sueño y la poesía comparten la esencia creativa.

El título "Me alquilo para soñar" es más probable que sea el enunciado que la propia Frida dice en el cuento: "-Me alquilo para soñar" (García, 1992, p. 95). Pero en ese contexto no se entiende del todo qué significa. A lo largo de las historias contadas por el narrador, se revela que tiene doble sentido. Uno es que el acto de soñar era el oficio y la fuente de ingresos que le permitía a la protagonista sobrevivir en Viena, reemplazando el pago de la renta de su vivienda con sus servicios de predicción. Otro, aunque soñar es su oficio toda su vida gira en torno al sueño y hasta su propósito de vida es soñar. Como señala Rodríguez Vergara (1994, pp. 345-359), la credibilidad de la profesión de Frida aumenta con sus predicciones convertidas en realidad y su oficio de soñar se convierte en una actividad estable. Su poder le otorga cierta autoridad y logra "apoderarse de la fortuna de sus inefables patrones de Viena" (García, 1992, p. 99). Sin embargo, a pesar de haber ganado una fortuna, la mujer sigue soñando. El sueño no es mera profesión sino su vida per se. En el final del cuento esta afirmación nuestra gana aún más claridad:

Y prosiguió [el embajador portugués] en el mismo tono, con detalles sorprendentes [sobre la vida de Frau Frida], pero sin una pista que me permitiera una conclusión final.

-En concreto, le precisé por fin-: ¿qué hacía?

-Nada -me dijo él, con un cierto desencanto-. Soñaba. (p. 101).

Los detalles que cuenta el embajador son las historias de la vida de la protagonista, de manera que la protagonista no solo soñaba para vivir: Frau Frida vivía para soñar. Ahora, sería posible establecer la ecuación soñar $=$ hacer poesía $=$ vivir. Pero desde el punto de vista del narrador-personaje, que cuestiona el poder del sueño y que al mismo tiempo se distancia del poeta, la ecuación es

\footnotetext{
${ }^{4}$ Bernardo Ortiz de Montellano (1990, p. 128), del grupo "Contemporáneos", dice: "y una vez más confirmo que en los sueños como en la poesía -estados psíquicos afines, imágenes de una realidad esencial- pueden anticiparse sucesos por venir".
} 
inaceptable. El narrador comenta que la convicción de Frida "era tan real" que hizo como ella le ordenó que hiciera:

— He venido sólo para decirte que anoche tuve un sueño contigo - me dijo-. Debes irte enseguida y no volver a Viena en los próximos cinco años.

Su convicción era tan real, que esa misma noche me embarcó en el último tren para Roma. Yo, por mi parte, quedé tan sugestionado, que desde entonces me he considerado sobreviviente de un desastre que nunca conocí. Todavía no he vuelto a Viena. (García, 1992, p. 97)

Aunque el narrador-personaje no acepta el sueño como un componente de la vida real, admite la creación onírica. La vida de Frida crea una realidad, no cuenta si el narrador-personaje confía o no en la correlación entre el evento y su predicción. Lo que importa es que se actualiza esa realidad creada por ella.

El narrador-personaje también es escritor, como se revela en la conversación final con el embajador portugués durante una recepción diplomática: “Usted no habría resistido la tentación de escribir un cuento sobre ella [Frida]." (García, 1992, p. 101). Probablemente, "Me alquilo para soñar" sería el cuento que escribe el narrador-escritor sobre Frau Frida después de dicha conversación. Entonces, ¿por qué habría escrito el narrador-personaje este cuento? El prólogo de la colección, otra vez, ofrece un indicio. El propósito de García Márquez fue escribir cuentos “basados en hechos periodísticos pero redimidos de su condición mortal por las astucias de la poesía" (p. 14). Rodríguez Vergara (1994, pp. 348-349) insiste en que los Doce cuentos peregrinos constituyen una metáfora del acto de escribir. Para la escritura del cuento, el narrador-personaje utiliza como base sus recuerdos, en vez del sueño. Los interpreta y crea una nueva versión de los recuerdos, que no coincidiría del todo con lo que fue o pasó verdaderamente. La creación imaginativa sería el mecanismo común a los tres personajes creadores, por el cual se crea la realidad pluridimensional del cuento. 


\section{La realidad latinoamericana}

A lo largo de los tiempos narrados, el espacio varía: La Habana, Viena, Quindío, Barcelona y otra vez La Habana. La capital cubana es donde se ubica el narrador en el presente del texto. También es donde muere Frau Frida. Quindío, el pueblo natal de la soñadora, solo aparece en el flashback al pasado más lejano. La protagonista salió del pueblo colombiano "entre las dos guerras" (García, 1992, p. 95) cuando era pequeña y vivió casi toda su vida en Europa hasta que murió en un accidente de vuelta a tierra latinoamericana. Aunque la mayoría de las historias que cuenta el narrador-personaje ocurren en ciudades europeas, lo latinoamericano siempre está presente tanto por los personajes como por el contraste con Europa que destaca la condición brutal para los latinoamericanos agobiados por la soledad y la nostalgia.

El narrador-personaje conoció a Frida en una taberna de estudiantes latinoamericanos que compartían "las estrecheces" (p. 97). En aquel tiempo, Viena se había convertido en "un paraíso del mercado negro y el espionaje mundial" (p. 95). Describe la ciudad como un "mundo tan distante y distinto" (р. 95). Frau Frida vivió en Porto después de retirarse, en una casa desde la que "se veía todo el océano hasta las Américas" (p. 99). Esta condición afecta la manera de vivir de la protagonista. Frida descubre su habilidad de pronosticar el futuro en Colombia. Ahí, el sueño era una cosa cotidiana y su poder, fácilmente aceptado y creído:

[...] y desde que aprendió a hablar instauró en la casa la buena costumbre de contar los sueños en ayunas, que es la hora en que se conservan más puras sus virtudes premonitorias. [...] La madre, ya convencida de las virtudes adivinatorias de la hija, hizo respetar la advertencia con mano dura. (pp. 95-96)

Este acto de soñar y pronosticar se convierte en un oficio debido a la dura realidad a la que se enfrenta en Europa: "Frau Frida no había pensado que aquella facultad pudiera ser un oficio, hasta que la vida la agarró por el cuello en los crueles inviernos de Viena." (p. 96). Antes, en su tierra vivía para soñar. pero en Europa tuvo que soñar para vivir. Si ubicamos ese cambio de vida en el contexto 
de la polaridad Europa / civilización / racionalismo y América Latina / barbarie / intuición, el poder creativo de la protagonista "se convierte en el único de los medios posibles de supervivencia para el otro en un entorno diferente", según Sanabria Sing (2001, p. 59). Lo onírico y lo imaginativo se atribuye a la identidad latinoamericana, mientras que el contraste entre Europa y los latinoamericanos les otorga una condición inevitable de soledad y nostalgia. La diferencia no necesariamente causa la soledad, sino que es el contraste lo que la condiciona. En el contexto donde se enfrentan ambas identidades, la latinoamericana se pierde y la europea se impone a la fuerza. Así, la pérdida de la identidad se encuentra en el núcleo de la soledad y de la nostalgia de los latinoamericanos.

Entre las tres dimensiones de vida que se han identificado, cada uno puede elegir su propia manera de vivir. Sin embargo, la selección está precondicionada para Frida. Ella tuvo que soñar para vivir, en vez de vivir para soñar. Esta sería la realidad solitaria que les sucede a los latinoamericanos en un mundo distante de su origen. En este sentido, la soledad se origina tanto por la distancia física como por el aislamiento psicológico y cultural. Su propia manera de vivir es negada por el racionalismo de los europeos. Como resultado, el sueño en vez de crear una nueva vida, debe utilizarse para mantenerse en la vida.

El cuento, sin embargo, no es pesimista. A través de la reconciliación entre sueño y poesía, se reivindica el valor creativo que tiene el sueño y se le concede validez a la vida como creación onírica. Aunque la realidad latinoamericana esté condenada a la soledad y a la nostalgia eterna en el contexto extranjero, se convierte en una forma válida de la vida. Si bien la poesía es clarividente, la vida de los sueños también es digna de apropiarse de la realidad por sí misma. El acto del narradorpersonaje de escribir el cuento sobre la vida de Frida funciona entonces como un testimonio de que ha habido una vida solitaria y al mismo tiempo creativa. De este modo, la realidad latinoamericana no termina en una condición predeterminada, sino que abre una posibilidad de sublimarse a una vida legítima. 


\section{Conclusión}

Las vidas representadas por las dimensiones en que se mueven los tres personajes de "Me alquilo para soñar", la vida como sueño, la vida de la poesía y la vida que narra, comparten como base común la creación. El mecanismo de la creación es el mismo: la imaginativa recreación. Por lo tanto, uno de los sentidos importantes del cuento es, como aclara García Márquez en el prólogo, que el sueño inspira la creación. La creación onírica, la poética y la de la narración empiezan con la selección de materiales objetivos y terminan con la imaginación que los libera de su condición 'mortal', otorgándoles una nueva vida imperecedera.

La vida de Frau Frida, sin embargo, se niega y decae en el medio europeo donde debe sobrevivir. Su manera de vivir pierde la esencia creativa y es explotada para mantenerse la vida. Así, el sueño se convierte en un mero objeto de la vida carente del poder de creación. Esta es la realidad solitaria a la que los latinoamericanos estarían condicionados en Europa. Aunque se le otorgara legitimidad a la vida como creación onírica, en Europa no se puede ejercer ese poder ni vivir como se vive en la tierra de su origen. Este aislamiento (o degradación) sería la realidad que García Márquez refleja en los Doce cuentos peregrinos.

La estructura del texto verosímil que invita al lector a contemplar la realidad de los latinoamericanos se encuentra a lo largo de los cuentos del libro. En "La santa", el segundo, el cadáver de la hija de Margarito Duarte desenterrada después de once años se encuentra intacto oliendo a rosas, pero el lector no cuestiona la veracidad del hecho narrado, sino que se fija en la vida del padre que "Ilevaba ya veintidós años luchando en vida" (García, 1992, p. 77) para que reconocieran a su hija como santa. El cuento invita al lector a la experiencia de sumersión y de contemplación, en la cual se encuentra la creencia y la forma de vida negadas en el contexto europeo. Esta interpretación se podría aplicar también en "Tramontana", "El verano feliz de la Señora Forbes" y "La luz es como el agua", entre otros. Doce cuentos peregrinos (2002) comparten la conciencia crítica de García Márquez presente en sus otras obras en donde, como en Cien años de soledad, denuncia la soledad de América Latina frente a la visión del mundo europeo. 


\section{Referencias}

Bal, M. (1990). Teoría de la narrativa. (Una introducción a la narratología). Trad. J. Franco. Madrid: Cátedra.

Booth, W. C. (1983). The Rhetoric of Fiction. Chicago: University of Chicago.

Brushwood, J. S. (1985). Reality and Imagination in the Novels of Garcia Marquez. Latin American Literary Review 13 (25), 9-14.

Chatman, S. (1978). Story and Discourse (pp. 146-151). Ithaca: Cornell University.

Gabás, R. (1990). El libre juego de facultades: belleza y conocimiento en Kant. Enrahonar. An International Journal of Theoretical and Practical Reason 16, 41-56.

García, G. (1992). Doce cuentos peregrinos. Madrid: Mondadori.

García, G. (2014). La soledad de América Latina. Discurso de aceptación del Premio Nobel 1982. Educere: Revista Venezolana de Educación 59, 167-170.

Garrido, M. Á. (2015). Diccionario español de términos literarios internacionales. Madrid: Consejo Superior de Investigaciones Científicas, Recuperado de http://www.proyectos.cchs.csic.es/detli/sites/default/files/Narratario.pdf

González, R. (1984). Cien años de soledad: The Novel as Myth and Archive. MLN 99 (2), 358-380.

Houvenaghel, E. (1999). La doble retórica de lo verosímil en Doce cuentos peregrinos. Neophilologus $83(1), 59-71$.

Kim, S. H. (2017). Invisible Line in the Korean Modern Novel Text. The Journal of Modern Literary Theory 70, 31-55.

Lee, K. M. (2019). Recepción de la literatura de Roberto Bolaño en Corea. Hispania 102 (2), 179-190. Ortiz, B. (1990). Raíces del sueño. México: Consejo Nacional para la Cultura y las Artes.

Rodríguez, S. (2018). Kafka y Brecht. Entre el hacha y el asombro. Medellín: Instituto Tecnológico Metropolitano.

Rodríguez, I. (1994). Escritura, creación y destrucción en Doce cuentos peregrinos de Gabriel García Márquez. Hispanic Journal 15 (2), 345-359. 
Sanabria, C. (2001). ¿Extraños peregrinos o extraño peregrinaje? Un acercamiento a los últimos cuentos de García Márquez. Filología y Lingüística 27 (1), 53-66.

Shelley, P. B. (1998). “A Defense of Poetry” (pp. 944-956). En Romanticism: An Anthology. Oxford: Blackwell. 